\title{
Ensino de avaliação psicológica: dificuldades relatadas por uma amostra de docentes brasileiros
}

\section{Psychological assessent teaching: Dificulties reported by a Brazilian teachers sample}

\section{Capacitación en evaluación psicológica: dificultades relatadas por una muestra de docentes brasileños}

\author{
Rodolfo Augusto Matteo Ambiel* \\ Universidade São Francisco - USF, Campinas, São Paulo, Brasil \\ Makilim Nunes Baptista** \\ Universidade São Francisco - USF, Campinas, São Paulo, Brasil
}

Marucia Patta Bardagi***

Universidade Federal de Santa Catarina - UFSC, Florianópolis, Santa Catarina, Brasil

\section{Acácia Aparecida Angeli dos Santos****}

Universidade São Francisco - USF, Campinas, São Paulo, Brasil

\begin{abstract}
RESUMO
Existem questões relativas ao ensino dos métodos e técnicas de Avaliação Psicológica (AP) que não têm sido suficientemente exploradas. Neste sentido, o presente estudo buscou identificar as dificuldades percebidas pelos docentes no ensino de avaliação psicológica nos cursos de graduação. Participaram do estudo 93 docentes $(67,7 \%$ mulheres $)$ de 13 estados brasileiros, com idades entre 24 e 63 anos, em uma amostra de conveniência. Os participantes responderam a uma questão aberta e as respostas foram submetidas à analise de conteúdo. Entre os resultados destaca-se que as categorias principais de resposta estiveram relacionadas à infraestrutura institucional; currículo dos cursos; atitude dos alunos e de docentes frente à disciplina; atuação docente em AP; psicólogos enquanto modelos de atuação. Os achados revelam a necessidade de um amplo debate sobre o ensino de avaliação psicológica de forma a favorecer a formação na área tanto em nível de graduação como na pós-graduação e apontam para a importância da criação de especialidade profissional na área. Palavras-chave: AP, ensino superior, formação do psicólogo.
\end{abstract}

\section{ABSTRACT}

There are issues relating to teaching methods and techniques of psychological assessment that have not been adequately explored. This paper intended to identify perceived dificulties of psychological assessment teachers. Participants were 93 teachers $(67.7 \%$ women) from 13 brazilian states, with ages ranging from 24 and 63 years old, selected by 
convenience. They answer an open question and the contents were analyzed. Results high lighted that main answers categories were related to institutional in frastructure, course curriculum, students and teachers aptittudes about psychological assessment, teaching performance in psychological assessment and psychologists as acting models. The findings show the need for a qualified debate, involving professionals and academics, about the teaching of psychological assessment in order to favor training in the area to the undergraduate and graduate students.

Keywords: PA, higher education, training of psychologists.

\section{RESUMEN}

Hay cuestiones relacionadas con los métodos de enseñanza y las técnicas de evaluación psicológica que no se han explorado adecuadamente. Por eso, este estudio busco identificar las dificultades encontradas por los docentes en la capacitación en evaluación psicológica en la educación superior .de este estudio participaron 93 docentes $(67,7 \%$ mujeres) de 13 estados brasileños, con edades entre 24 y 63 años, en una muestra de conveniencia. Los participantes respondieron a una pregunta abierta, y las respuestas fueron sometidas a análisis de contenido. Entre los resultados se destaca que las principales categorías en las respuestas estaban relacionadas con: infraestructura institucional; currículo de los cursos; actitud de los alumnos y de los docentes delante de la EP; actuación docente en EP; psicólogos en cuanto modelos de actuación. Los hallazgos demuestran la necesidad de un debate cualificado, involucrando a profesionales y académicos, sobre la enseñanza de la evaluación psicológica para favorecer la formación en el área a los estudiantes de pregrado y postgrado.

Palabras-clave: EP, educación superior, formación del psicólogo.

\section{I ntrodução}

As preocupações com o ensino da Psicologia estão há muito tempo presentes na literatura PSI brasileira. Estudos em diferentes áreas problematizam a formação do psicólogo, a formação docente e os impactos das mudanças curriculares para o ensino da Psicologia como ciência e profissão (Abdalla, 2007; Abdalla, Batista, \& Batista, 2008; Azzi, Almeida, \& Ferreira, 2007; Bandeira, 2011; Del Prette, 1991; Fontoura \& Silva, 2013; Gomes, 1996; Magalhães, 2013; Noronha, 2003; Rosa, 2001; Vilela, 2012). No geral, estes estudos discutem a necessidade de superar as diferenças ideológicas dentro dos cursos e áreas, a inclusão de uma integração mais consistente entre teoria e prática profissional e a adequação da formação às demandas em transformação no campo da Psicologia enquanto profissão. Especificamente, a discussão da formação também tem sido premente na área da avaliação psicológica.

Tal preocupação, no Brasil, tem se dado frente a um histórico de críticas acerca da área. Especialmente até a década de 1990, não se observava, de forma geral, um empenho por parte dos próprios profissionais para realizar avaliações consistentes, com cuidado com a qualidade técnica dos instrumentos. Apesar dos avanços técnicos 
observados a partir do início da década de 2000, a formação parece não ter acompanhado o movimento, tendo sido observadas recentemente reduções na carga horária de disciplinas de avaliação em diversas instituições, muitas vezes transformando o ensino da avaliação psicológica em um mero treinamento mecânico para o uso dos testes (Noronha \& Reppold, 2010; Reppold \& Serafini, 2010). Nesta mesma direção, Primi (2010) afirma que a má formação na área tende a perpetuar preconceitos simplistas e acríticos relativos à AP, o que sinaliza também a pouca importância atribuída ao ensino da psicologia numa perspectiva científica nas universidades brasileiras.

Contudo, alguns pesquisadores têm se dedicado a compreender o processo de ensino e aprendizagem da avaliação psicológica por meio de investigações com discentes e docentes de cursos de psicologia, cujos resultados são sinteticamente apresentados a seguir, Ao avaliarem profissionais sobre a sua formação para uso de instrumentos, Azevedo, Almeida, Pasquali e Veiga (1996) identificaram, por meio de entrevistas, que os psicólogos de Brasília consideraram a formação profissional apenas razoável. A pesquisa de Paula, Pereira e Nascimento (2007) ocorreu com 358 alunos de Psicologia de instituições de Belo Horizonte, e os resultados indicaram que a maioria deles considerou a formação em avaliação insuficiente. Além disso, desconheciam a Resolução 02/2003 do CFP, que define critérios relacionados à produção e comercialização de instrumentos.

Em outra pesquisa, com estudantes de Psicologia da região CentroOeste, Noronha, Nunes e Ambiel (2007) identificaram grande diversidade nos títulos das disciplinas cursadas, Segundo os autores, esta diversidade de títulos pode indicar uma falta de consenso sobre o que é essencial para o ensino das disciplinas de AP. Outro achado relevante foi que mesmo os alunos atribuíam maior importância e demonstravam maior conhecimento sobre os aspectos éticos envolvidos na avaliação psicológica, conferiam menor importância ao domínio de estatística, bem como a aspectos da Psicometria, à construção de instrumentos e ao conhecimento de construtos psicológicos, todos fundamentais no ensino da avaliação (APA, 2000; Borsa, 2016; Noronha et al., 2002; Noronha, Carvalho, Miguel, Souza, \& Santos, 2010). Nesta mesma direção, Vendramini, Silva e Dias (2009) também constataram que a atitude dos estudantes de psicologia em relação à estatística tende a ser mais negativa do que positiva.

Relativo aos estudos já realizados com professores, dois deles mostram o predomínio da ênfase na formação tecnicista. O de Alves, Alchieri e Marques (2002) contou com a participação de 172 docentes de disciplinas de Técnicas de Exame Psicológico, de 62 cursos de Psicologia de várias regiões do país. À época, os resultados indicaram que o número de testes que ensinavam era superior ao que 
consideravam como instrumentos básicos para o ensino de AP. Anos depois, Noronha, Castro, Ottati, Barros e Santana (2013) detectaram que a maioria dos docentes ensina conteúdos relativos às técnicas de avaliação e fundamentos teóricos dos testes, recorrendo a aulas expositivas. Os autores observaram que aspectos relativos aos fundamentos da Psicometria, a ética na avaliação e a contextualização da área de avaliação dentro da história da Psicologia eram menos abordados.

Um terceiro estudo com professores realizado por Noronha, Barros, Nunes e Santos (2014) com 98 docentes de diversas disciplinas ministradas em cursos de psicologia consideraram as atividades de conhecer e aplicar conceitos éticos e legais dos processos de avaliação, bem como as condições ideais de aplicação e comunicação de resultados como altamente importantes. Por outro lado, ter noções de estatística, conhecer uma ampla gama de testes e de conceitos de psicometria foram considerados menos importantes. Ainda, nesse mesmo estudo, foi identificado que os professores formados há menos tempo consideram mais importante conhecer psicopatologia, saber elaborar um parecer, ter noções de estatística e entender os estudos de validade e precisão do que aqueles formados há mais tempo. A expectativa expressa pelos autores é de que a mudança detectada pode ser atribuída à formação pós-graduada desses docentes que pode ter promovido uma visão mais ampliada do processo de avaliação como um todo.

Ao estudarem o domínio de conceitos essenciais da avaliação psicológica em estudantes e profissionais, Mendes, Nakano, Silva e Sampaio (2013) observaram que não havia diferenças significativas entre os grupos em relação aos conhecimentos sobre os temas investigados (incluindo conceitos de validade e precisão, o Sistema de Avaliação de Testes Psicológicos - SATEPSI, os requisitos para aprovação de testes, a definição de avaliação, etc.). Ademais, muitas respostas erradas ou em branco foram identificadas nos questionários respondidos, o que foi interpretado pelas autoras como uma deficiência importante na formação na área.

Os poucos estudos brasileiros realizados com professores, ficaram predominantemente restritos à identificação de estruturas, conteúdos e estratégias docentes, concedendo pouco atenção ao que os professores revelam sobre as dificuldades para o ensino da Avaliação Psicológica. Todos eles, contudo, sugerem a importância da realização de novas investigações. Tendo em vista tais questões, pesquisadores integrantes do GT Pesquisas em Avaliação Psicológica da Associação Nacional de Pesquisa e Pós-Graduação em Psicologia (ANPEPP), tiveram como intuito mapear o ensino de Avaliação Psicológica no país. Nesse sentido, realizaram a pesquisa aqui relatada com o objetivo de identificar o perfil de formação de professores que ministram disciplinas de avaliação psicológica em 
cursos de Psicologia do Brasil e, em especial, as dificuldades que encontram em seu exercício de docência.

\section{Método}

\subsection{Participantes}

Participaram desta pesquisa 93 docentes de avaliação psicológica, sendo $67,7 \%$ do sexo feminino, com idades variando entre 24 e 63 anos $(M=39,5 ; D P=10,05)$. No momento da pesquisa, a maioria dos participantes atuava em instituições particulares $(n=54 ; 58,1 \%)$ de diversos estados brasileiros, sendo que 25 foram de São Paulo $(26,9 \%), 16$ de Minas Gerais $(17,2 \%), 12$ do Rio Grande do Sul $(12,9 \%)$ e 10 no Paraná $(10,8 \%)$ foram aqueles com mais respondentes. A experiência média na atividade docente foi de 16 semestres. Entre os docentes que responderam sobre a carga horária semanal, parte atuava com carga horária semanal de 40 horas com dedicação exclusiva $(n=27 ; 29 \%)$, outros possuíam entre 20 e 40 horas semanais $(n=22 ; 23,7 \%)$ e os demais menos de 20 horas $(n=$ $24 ; 25,8 \%)$.

Por fim, importa destacar que 29 docentes (31,2\%) afirmaram exercer apenas a docência, sem atividades práticas relacionadas à avaliação psicológica. No entanto, mesmo que muitos não tivessem atuação prática em avaliação psicológica, a maioria declarou frequentar eventos ( $n=89 ; 96 \%$ ), que tinham artigos ou capítulos de livros publicados $(n=71 ; 77 \%)$ e que já haviam orientado na pós-graduação ou realizado pesquisas $(\mathrm{n}=79 ; 85 \%)$ na área de avaliação nos últimos cinco anos.

Em relação à formação, 45 docentes não responderam sobre a sua área de especialização, sendo que do restante, apenas três participantes mencionaram a área específica da avaliação psicológica. Quanto à formação em Stricto Sensu, apenas 13 docentes não responderam. Do restante, 23 disseram que seus cursos de mestrado ou de doutorado foram na área de avaliação psicológica. Dentre os doutores $(n=40)$, sete também já haviam feito pós-doutoramento.

\subsection{I nstrumento}

Para a coleta de dados recorreu-se a um formulário online com itens de identificação, formação e atividade docente. A versão inicial do questionário foi baseada em um instrumento utilizado em pesquisa anterior (Alves et al., 2002, 2001). Eram solicitadas informações sobre o envolvimento com a área psicológica para além da docência, como publicação, orientação de pesquisa e participação em eventos e de sociedades científicas; informações sobre o curso de Psicologia; 
disciplinas ministradas na área de avaliação psicológica, conteúdo trabalhado, recursos materiais e ambientais disponíveis, atividade prática e de supervisão. Em seguida, era proposta uma questão aberta referente às dificuldades sentidas pelo professor no exercício do magistério em avaliação psicológica. Os dados obtidos com as questões iniciais do questionário foram posteriormente usados para a compreensão e discussão dos dados obtidos com a questão aberta.

\subsection{Procedimentos e Considerações Éticas}

A coleta de dados teve início após a aprovação do projeto pelo Comitê de Ética para Pesquisas com Seres Humanos da Universidade Federal do Rio Grande do Sul ( $n$ o 2011034). O contato com os participantes da pesquisa foi estabelecido via mensagem eletrônica, a partir de contato com os coordenadores dos cursos de Psicologia por meio de listagem disponibilizada pela Associação Brasileira de Ensino de Psicologia (ABEP, instituição que concordou em colaborar com o estudo) e por contatos identificados nos sites dos cursos. Após a indicação dos professores envolvidos nas disciplinas de avaliação psicológica do curso, tais docentes receberam informações sobre a pesquisa e o endereço de uma home page específica para registro da sua participação. A coleta de dados foi realizada pela aplicação do questionário via web com acesso restrito aos participantes e pesquisadores. Em termos éticos, o livre consentimento foi garantido tanto pela leitura do Termo de Consentimento Livre e Esclarecido (TCLE) ao clicar no ícone que indica decisão de participar do estudo, quanto ao término do preenchimento e envio do mesmo ao banco de dados, confirmando novamente sua intenção em participar (Oliveira, 2006). Mesmo diante da confirmação e o envio das respostas, o participante que quisesse ainda poderia encaminhar uma mensagem ao e-mail indicado no TCLE e solicitar sua exclusão.

\subsection{Análise de dados}

A questão formulada sobre as dificuldades encontradas pelos docentes quanto ao ensino de avaliação psicológica resultou do foco estabelecido no presente estudo. Após a pergunta, havia espaço aberto para que os participantes pudessem escrever suas opiniões. Os dados eram registrados automaticamente em planilha eletrônica. Após a extração das respostas, todas foram lidas na íntegra. No total, foram registradas 136 respostas, que compuseram as 134 unidades corpus da análise de conteúdo categórica (Bardin, 1977) em razão de que uma continha duas ideias que foram analisadas separadamente. Outras três respostas estavam sem sentido, possivelmente devido a erros de digitação e foram desconsideradas. 


\section{Resultados}

A análise de conteúdo do material revelou a presença de seis categorias temáticas. A Tabela 1 exibe os nomes das categorias, a frequência e exemplos de unidades referentes a cada categoria.

Tabela 1.

Categorias relativas às dificuldades no ensino da avaliação psicológica

\begin{tabular}{|c|c|c|}
\hline Categoria & $\begin{array}{l}\text { Quantidade } \\
\text { de unidades }\end{array}$ & Exemplos de unidades \\
\hline $\begin{array}{l}\text { Infraestrutura } \\
\text { institucional }\end{array}$ & $39(29,5 \%)$ & $\begin{array}{l}\text { "Falta de instrumentos suficientes para todos os } \\
\text { alunos"; "Número elevado de alunos por turma"; } \\
\text { "Local adequado que sirva como laboratório de } \\
\text { medidas e avaliação psicológica" }\end{array}$ \\
\hline Currículo & $30(22,7 \%)$ & $\begin{array}{l}\text { "Carga horária reduzida"; "Desconexão com outras } \\
\text { disciplinas do curso"; "poucas disciplinas da área com } \\
\text { conteúdo excessivo" }\end{array}$ \\
\hline $\begin{array}{l}\text { Atitudes dos } \\
\text { alunos }\end{array}$ & $29(22 \%)$ & $\begin{array}{l}\text { "Deficiência dos alunos em métodos quantitativos"; } \\
\text { "Desinteresse pelo que é relativo à testagem } \\
\text { psicológica"; }\end{array}$ \\
\hline $\begin{array}{l}\text { Atitudes de } \\
\text { outros } \\
\text { docentes }\end{array}$ & $24(18,2 \%)$ & $\begin{array}{l}\text { "A doutrinação de professores de outras disciplinas } \\
\text { contra a avaliação psicológica e os testes psicológicos, } \\
\text { levando a resistências e críticas dos alunos"; } \\
\text { "Descrédito nos testes e na avaliação psicológica" }\end{array}$ \\
\hline $\begin{array}{l}\text { Atuação } \\
\text { docente em } \\
\text { AP }\end{array}$ & $7(5,3 \%)$ & $\begin{array}{l}\text { "professores muito teóricos que não tem a prática"; } \\
\text { "ser a única docente da área no curso" }\end{array}$ \\
\hline $\begin{array}{l}\text { Profissionais } \\
\text { como } \\
\text { modelos }\end{array}$ & $3(2,3 \%)$ & $\begin{array}{l}\text { "Realização equivocada de processos de avaliação } \\
\text { psicológica por profissionais já formados, que acabam } \\
\text { servindo de parâmetro para os acadêmicos" }\end{array}$ \\
\hline
\end{tabular}

Note-se que a ordem das categorias foi determinada pela quantidade de unidades. Foi possível identificar uma grande diferença na ocorrência das duas últimas categorias em relação às demais.

A categoria 'Infraestrutura institucional' foi definida por agrupar unidades referentes a dificuldades relacionadas ao não oferecimento de condições básicas adequadas por parte da instituição. A categoria 'Currículo' aglutinou dificuldades relativas às disciplinas e atividades que são desenvolvidas nos cursos de graduação que pouco contemplam a área de avaliação psicológica. As 'Atitudes dos alunos' foi a terceira categoria e referiu-se tanto a dificuldades referentes a deficiências dos alunos quanto à aprendizagem de conteúdos anteriores, como também dificuldades específicas (e.g. redação de textos) e desinteresse, incluindo, ainda, comentários sobre a postura ética inadequada dos alunos. A quarta categoria, intitulada 'Atitudes de outros docentes', diz respeito a dificuldades relativas à visão e atitudes negativas e ideológicas que outros docentes têm em relação à avaliação psicológica.

As duas últimas categorias foram a 'Atuação docente em avaliação psicológica' que agrupou unidades de texto referentes a dificuldades 
relativas à docência na área de $A P$, que incluem a escassez de professores e o despreparo teórico, técnico e prático para lecionar tais disciplinas. A sexta e última categoria 'Profissionais como modelos' abordou dificuldades relativas a práticas de avaliação inadequadas que profissionais da AP exercem fora da universidade e que fornecem modelos inadequados aos alunos.

\section{Discussão}

Considerando o objetivo proposto, e tomando por base cada uma das categorias extraídas do material coletado várias reflexões foram realizadas. A primeira categoria, denominada 'Infraestrutura Institucional' se referiu principalmente à falta de espaços físicos específicos para a prática da $A P$, ao número reduzido de manuais e de folhas de respostas e de crivos. Por último, ficou explícito o desafio de lidar com uma grande quantidade de alunos por turma. Tais respostas apontam para 0 baixo investimento feito pelas Instituições de Ensino Superior (IES) tanto públicas como privadas que, por motivos diferentes, têm baixo nível de investimento na área. As primeiras lidam com a escassez de verbas que se acentuou nos últimos anos e as segundas com a pressão constante para redução de custos e aumento da margem de lucros.

Além disso, esse tipo de queixa pode também estar relacionada à ênfase do ensino, muito mais voltado à exposição dos testes do que ao ensino crítico que seria desejável. Observação similar foi realizada anteriormente por Alves et al. (2002) e Noronha et al. (2013). É mais um elemento que mostra que o ensino tem se afastado das questões processuais e dos fundamentos da Avaliação Psicológica.

Como apontam Primi (2010) e Noronha e Reppold (2010), apesar do desenvolvimento da AP no Brasil, a formação parece não ter acompanhado esse crescimento no mesmo ritmo. Por exemplo, com uma amostra de docentes de AP, Noronha et al. (2013) descrevem que um dos apontamentos nos resultados diz respeito ao foco no ensino específico dos testes e, não necessariamente nos fundamentos psicométricos da AP, ou seja, revelam um ensino tecnicista. A gravidade inerente a este tipo de ensino está no tipo de profissional que será formado, que saberá apenas utilizar os testes específicos, em cujo uso foram treinados. Faltarão elementos de raciocínio crítico que lhes permitirão pensar na situação-problema e procurar entre os muitos instrumentos de avaliação psicológica e não apenas nos testes, que seriam os mais apropriados para o uso em cada situação, considerando também o contexto e o propósito da avaliação (Anache \& Corrêa, 2010; Anache \& Reppold, 2010).

Como observado nos resultados, diversas categorias foram agrupadas para a explicação das principais dificuldades encontradas. Assim, 
independentemente do foco na técnica ou no processo, é importante salientar que o ensino, seja ele de AP ou de quaisquer outras disciplinas específicas, necessita de locais adequados para a prática e da disponibilização de materiais que forneçam o suporte necessário para que o aluno possa manusear os materiais durante a aprendizagem da técnica. Esta questão também pode demonstrar algum descrédito que professores da área revelam, visto que suas necessidades não são consideradas prioritárias em relação a espaços adequados e/ou distribuição de verbas institucionais.

Complementarmente, um outro resultado obtido na atual pesquisa foi o referente às críticas que docentes de outras disciplinas teceram sobre a utilização dos testes psicológicos. Tal descrédito por parte do corpo docente também poderia estar estimulando a cultura de não investimento institucional na área. Nesse sentido, é preciso que os professores e também os pesquisadores da área de avaliação, ao discutirem diretrizes e indicações para a formação, não pensem apenas em termos de conteúdos relevantes (Noronha et al., 2002, 2010; Nunes et al., 2012), mas também se preocupem em problematizar as estruturas desejáveis e adequadas para o ensino da avaliação.

Além das questões já mencionadas, os docentes têm percepção de que os próprios alunos são desinteressados e apresentam sérias deficiências para 0 uso de métodos quantitativos. A respeito, Vendramini et al. (2009) identificaram em uma amostra de estudantes de Psicologia, maior tendência para a demonstração de atitudes negativas frente ao uso de métodos estatísticos. Como a psicometria se utiliza basicamente de conceitos estatísticos, a associação entre a AP e a estatística pode desmotivar os alunos para o aprendizado das disciplinas relacionadas à temática.

Outro ponto importante, na opinião dos docentes, está relacionado à carga horária reduzida das disciplinas AP e à falta de integração da AP com outras disciplinas e estágios que poderiam estar vinculados à área. De fato, as disciplinas de AP, bem como as cargas horárias vêm sofrendo diminuição em diversos cursos (Noronha \& Reppold, 2010). No entanto, iniciativas isoladas que surgem quando os coordenadores possuem maior conhecimento sobre o tema e/ou têm inserção política na área, podem ser observadas, o que possibilita uma distribuição mais equitativa da carga horária nas disciplinas de AP, bem como promovem a integração das disciplinas da AP com outras disciplinas do currículo, tal como recomendado por Reppold e Serafini (2010).

Como atividade transversal, que define o fazer psicológico (CFP, 1992) e se constitui em um dos eixos estruturantes da formação (BRASIL, 2011), a avaliação psicológica apresenta inúmeras possibilidades de integração com outros campos da psicologia, como psicologia da saúde, psicologia escolar/educacional, psicologia do 
trabalho, psicologia jurídica, psicologia do esporte, neuropsicologia, entre muitas outras. Assim, é importante que os professores de AP possam promover a reflexão sobre essa integração com os alunos, sem deixar de contemplar a discussão com os colegas das demais disciplinas. Além disso, tomando como referência o que acontece em vários dos cursos de especialização na área, o estudo da avaliação psicológica aplicada aos diferentes campos também poderia ser uma estratégia para enfrentar o isolamento da área nos cursos de psicologia, referido por vários participantes do estudo.

Nos resultados da presente pesquisa, pode-se notar que duas categorias apareceram com frequência bem menor dos que as demais já citadas. Apesar de menos frequentes, estas categorias apontam para aspectos importantes para o debate das questões da área. Por exemplo, a 'Atuação Docente em Avaliação Psicológica' agrupou unidades referentes à escassez de professores especialistas, que tenham não só conhecimento teórico sólido, mas também experiência prática. É interessante perceber que os participantes relataram dificuldades, não apenas relativas à crítica e preconceito de docentes de outras disciplinas, fomentando a resistência dos alunos, mas, também, dos próprios docentes da área, que muitas vezes não são capacitados para prover o ensino com o nível de aprofundamento esperado. Em acréscimo, a última categoria observada diz respeito a dificuldades de ensino para alunos que se tornam refratários aos conteúdos de AP, em razão de experiências observadas fora do contexto universitário, relativas a processos conduzidos de forma equivocada e inadequada por psicólogos já formados. Estas duas categorias de dificuldades agrupadas a partir dos resultados poderiam ser bastante minimizadas com a criação de especialidade profissional em Avaliação Psicológica. Há mais de 10 anos o Instituto Brasileiro de Avaliação Psicológica (IBAP) e a Associação Brasileira de Rorschach e Métodos Projetivos (ASBRo) têm feito gestões junto ao Sistema Conselhos de Psicologia para a criação desta especialidade. Contudo, na visão dos conselheiros que integram a Assembleia de Políticas, da Administração e das Finanças (APAF), a avaliação psicológica é uma área de atuação de todos os psicólogos e têm rejeitado a proposta.

Os dados aqui apresentados reforçam os achados de outras pesquisas (Mendes et al, 2013; Noronha et al., 2014) que indicam a necessidade de formação continuada dos profissionais, especialmente daqueles formados há mais tempo. De forma específica, as queixas dos professores parecem estar de acordo com as ideias de Noronha e Reppold (2010), Primi (2010), Bandeira (2011) e Borsa (2016), que defendem um aprofundamento da formação pós-graduada do profissional, tanto no formato Lato Sensu quanto no Strictu Sensu. O conteúdo trazido pelos alunos reforça sobremaneira os achados de estudiosos dedicados ao estudo do ensino de Avaliação Psicológica, mostrando que apesar dos avanços existentes no conhecimento em 
psicometria e em métodos de diagnóstico, como ilustrado pelos vários artigos publicados na revista exclusiva da área (Avaliação Psicológica), que desde 2014 galgou o status de revista A2 na avaliação dos periódicos da CAPES, os problemas continuam muito semelhantes.

\section{Considerações finais}

O presente estudo teve o objetivo de levantar as dificuldades no ensino de avaliação psicológica por parte de docentes de cursos brasileiros. Inicialmente, a coleta online planejada tinha o intuito de facilitar o acesso a uma amostra representativa e diversificada do ponto de vista geográfico. Mesmo o link tendo ficado aberto por mais de oito meses de forma ininterrupta e sido divulgado diversas vezes, por email e redes sociais, considera-se que a quantidade de docentes abordada não foi suficiente para se caracterizar a amostra como sendo representativa. Esta pode ser considerada uma limitação do estudo, uma vez que não permite fazer generalizações ou conhecer de forma pormenorizada as dificuldades encontradas, por exemplo, por docentes atuantes em diferentes regiões do Brasil ou em instituições com diferentes categorias administrativas. Em estudos futuros, deve-se procurar abranger de forma mais direta os docentes ou conscientizá-los da importância da adesão a esse tipo de pesquisa para a sua prática.

Contudo, pode-se concluir que uma dificuldade apontada recai, ainda que indiretamente, sobre a formação dos professores de AP. Considerando que a formação dos profissionais depende em grande parte dos estímulos e da organização das disciplinas na graduação, os resultados mostraram que algumas das dificuldades encontradas em sala de aula dizem respeito à relação com professores de outras disciplinas. Tal fato só pode ser superado por um debate aberto no âmbito do projeto pedagógico do curso. Em quaisquer das ênfases possíveis que tenham sido escolhidas, cabe ao corpo docente a pergunta sobre como se encaixa a avaliação psicológica, que em termos da legislação vigente (Decreto-lei no 53.464) é uma das poucas atividades que diferenciam o profissional psicólogo de outros profissionais da área da saúde e das áreas de humanas.

Das respostas dos professores se depreende o reconhecimento de preconceitos e desinteresse dos próprios alunos com a avaliação psicológica em geral e com os testes psicológicos, em particular. Implícito nesse discurso aparece o fato de que a formação em AP na graduação em psicologia parece carecer de fundamentos e de argumentos para convencer os estudantes da importância dessa prática para o futuro psicólogo. Assim, investimentos também na formação do docente se fazem importantes. Mais uma vez o debate 
em reuniões dos colegiados ou dos departamentos frente aos avanços do conhecimento na área de Avaliação Psicológica poderão fazer avançar as posições em relação à importância do ensino dos princípios teóricos e da aplicação prática dele derivados. A formação continuada dos professores e dos profissionais, sem dúvida contribuirão para a alteração do quadro aqui delineado (Borsa, 2016; Noronha et al, 2013; Primi, 2010).

Dessa forma, do ponto de vista da formação pós-graduada no Stricto Sensu, há a necessidade da abertura de mais linhas de pesquisa nos programas que atendam a demanda de formar adequadamente pesquisadores na área. Por outro lado, e de forma destacada, a formação prática em AP poderia favorecer a reclamada integração com outras disciplinas. Para tanto, uma discussão que não pode ser esquecida diz respeito ao reconhecimento por parte do Conselho Federal de Psicologia da avaliação psicológica como uma área de especialidade. Assim, este artigo é mais um a apontar a pertinência desta discussão e a afirmar que os argumentos contrários a essa proposta parecem ter um fundamento muito mais ideológico do que prático.

O reconhecimento da Avaliação Psicológica como uma especialidade da Psicologia poderia, no futuro, minimizar as muitas dificuldades técnicas dos profissionais, proporcionando melhor atuação prática e o merecido reconhecimento social, mesmo dentro da própria profissão. Consequentemente, acredita-se que a atitude dos estudantes poderia se tornar mais positiva em relação à área e proporcionar uma continuidade nos estudos, tão necessária em toda e qualquer área de atuação do psicólogo, dada a complexidade das questões envolvidas.

\section{Referências}

Abdalla, I. G. (2007). O ensino de Psicologia Clínica na graduação: uma análise a partir de psicólogos clínicos docentes e não docentes. Revista Brasileira de Educação Médica, 31(2), 190.

Abdalla, I. G., Batista, S. H., \& Batista, N. A. (2008). Desafios do ensino de psicologia clínica em cursos de Psicologia. Psicologia: Ciência e Profissão, 28(4), 806-819.

Alves, I. C. B., Alchieri, J. C., \& Marques, K. C. (2001). Panorama geral do ensino das técnicas de exame psicológico no Brasil. In Anais do I Congresso de Psicologia Clínica (pp. 102-106). São Paulo: Universidade Presbiteriana Mackenzie.

Alves, I. C. B., Alchieri, J. C., \& Marques, K. C. (2002). As técnicas de exame psicológico ensinadas nos cursos de graduação de acordo com os professores. Psico-USF, 7(1), 77-88. 
American Psychological Association. (2000). Report of the task force on test user qualifications. Washington: American Psychological Association.

Anache, A. A., \& Corrêa, F. (2010). As políticas do Conselho Federal de Psicologia para a Avaliação Psicológica. In A. A. A. Santos et al (Orgs.), Avaliação Psicológica: diretrizes na regulamentação da profissão (pp. 19-30). Brasília: Conselho Federal de Psicologia.

Anache, A. A., \& Reppold, C. T. (2010). Avaliação Psicológica: implicações éticas. In A. A. A. Santos et al (Orgs), Avaliação Psicológica: diretrizes na regulamentação da profissão (pp. 5785). Brasília: Conselho Federal de Psicologia.

Azevedo, M. M., Almeida, L. S., Pasquali, L., \& Veiga, H. M. S. (1996). Utilização dos testes psicológicos no Brasil: dados de estudo preliminar em Brasília. In L. S. Almeida, S. Araújo, M. M. Gonçalvez, C. Machado, \& M. R. Simões (Orgs.). Avaliação psicológica: formas e contextos (Vol. 4, pp. 213-219). Braga, Portugal: Associação dos Psicólogos Portugueses.

Azzi, R. G., Almeida, P. C. A., \& Ferreira, L. C. M. (2007). Ensino de Psicologia em cursos superiores: problematizando desafios. Contraponto, 7(2), 383-404.

Bandeira, D. R. (2011). Repensando a formação em avaliação psicológica no Brasil. Em Conselho Federal de Psicologia, Ano da avaliação psicológica - Textos geradores (pp. 129-132). Brasília, DF: Conselho Federal de Psicologia.

Bardin, L. (1977). Análise de conteúdo. Lisboa: Edições 70.

Borsa, J. (2016). Considerações sobre a formação e a prática em avaliação psicológica no Brasil. Temas de Psicologia, 24(1), 131143.

BRASIL. (1964). Decreto-lei no 53.464 de 21 de janeiro de 1964. Regulamenta a Lei no 4.119, de agosto de 1962, que dispõe sobre a Profissão de Psicólogo. Retirado de http://www.pol.org.br/arquivos_pdf/decreto_n_53.464-64.pdf

BRASIL. (2011). Ministério da Ėducação. Conselho Nacional de Educação. Diretrizes curriculares nacionais para os cursos de graduação em Psicologia. Resolução CNE/CES, № 5, de 15 de março. Diário Oficial da União: Brasília, DF.

BRASI L. (2011, 16 mar.). Ministério da Educação, Conselho Nacional de Educação. Câmara de Educação Superior. Resolução no 5, de 15 de março de 2011. Institui as Diretrizes Curriculares Nacionais para os cursos de graduação em Psicologia. Diário Oficial da União, Seção 1, 19.

Conselho Federal de Psicologia - CFP. (1992). Atribuições Profissionais do Psicólogo no Brasil. Contribuição do Conselho Federal de Psicologia ao Ministério do Trabalho para integrar o catálogo brasileiro de ocupações. Manuscrito não publicado. 
Retirado

de www.site.cfp.org.br/wpcontent/uploads/2008/08/atr_prof_psicologo.pdf

Del Prette, A. (1991). O ensino da Psicologia Social: a opção preferencial pela concomitância teoria-prática. Paidéia, 1, 53-59.

Fontoura, M. H., \& Silva, J. C. (2013). O ensino de psicologia inserido nos cursos técnicos: um relato de experiência através da docência em psicologia do trabalho. Revista Reflexão e Ação, 21(n. esp.), 242-260.

Gomes, W. B. (1996). Pesquisa e ensino em Psicologia: articulações possíveis entre pós-graduação e graduação. In R. M. L. L. Carvalho (Org.), Repensando a formação do psicólogo: da informação à descoberta (Coletâneas ANPEPP n. 9) (pp. 33-50). Campinas: Editora Alínea.

Magalhães, S. M. O. (2013). Ensino de Psicologia: limites do atual paradigma e a complementaridade do paradigma da complexidade. Educação em Revista, 48, 265-287.

Mendes, L. S., Nakano, T. C., Silva, I. B., \& Sampaio, M. H. L. (2013). Conceitos de avaliação psicológica: conhecimento de estudantes e profissionais. Psicologia: Ciência e Profissão, 33(2), 428-445.

Noronha, A. P. P. (2003). Docentes de psicologia: formação profissional. Estudos de Psicologia (Natal), 8(1), 169-173.

Noronha, A. P. P., Barros, M. V. C., Nunes, M. F. O., \& Santos, A. A. A. (2014). Avaliação psicológica: importância e domínio de atividades segundo docentes. Estudos e Pesquisas em Psicologia, 14(2), 524-538.

Noronha, A. P. P., Carvalho, L. F., Miguel, F. K., Souza, M., \& Santos, A. A. A. (2010). Sobre o ensino de avaliação psicológica. Avaliação Psicológica, 9(1), 139-146.

Noronha, A. P. P., Castro, N. R., Ottati, F., Barros, M. V. C., \& Santana, P. R. (2013). Conteúdos e metodologias de ensino de avaliação psicológica: um estudo com professores. Paidéia, 23(54), 129-139.

Noronha, A. P. P., Nunes, M. F. O., \& Ambiel, R. A. M. (2007). Importância e domínios de avaliação psicológica: um estudo com alunos de Psicologia. Paidéia (Ribeirão Preto), 17(37), 231-244.

Noronha, A. P. P., \& Reppold, C. T. (2010). Considerações sobre a avaliação psicológica no Brasil. Psicologia: Ciência e Profissão, 30(n. esp.), 192-201.

Noronha, A. P. P., Ziviani, C., Hutz, C. S., Bandeira, D. R., Custódio, I. C. B. A., Alchieri, J. C., Borges, L. O., Pasquali, L., Primi, R., \& Domingues, S. F. (2002). Em defesa da avaliação psicológica. Avaliação Psicológica, 1(1), 173-174.

Nunes, M. F. O., Muniz, M., Reppold, C. T., Faiad, C., Bueno, J. M. H., $\&$ Noronha, A. P. P. (2012). Diretrizes para o ensino de avaliação psicológica. Avaliação Psicológica, 11(2), 309-316. 
Oliveira, J. A. C. (2006). Qualidade de vida e desempenho acadêmico de graduandos (Tese de Doutorado). Universidade Estadual de Campinas, Campinas, SP.

Paula, A. V., Pereira, A. S., \& Nascimento, E. (2007). Opinião de alunos de psicologia sobre o ensino em avaliação psicológica. Psico-USF, 12(1), 33-43.

Primi, R. (2010). Avaliação Psicológica no Brasil: Fundamentos, situação atual e direções para o futuro. Psicologia: Teoria e Pesquisa, 26(n. esp.), 25-35.

Reppold, C. T., Serafini, A. J. (2010). Novas tendências no ensino da Avaliação Psicológica. Avaliação Psicológica, 9(2), 323-329.

Rosa, M. D. (2001). Psicanálise na universidade: considerações sobre o ensino de psicanálise nos cursos de Psicologia. Psicologia USP, 12(2), 189-199.

Vilela, A. M. J. (2012). História da Psicologia no Brasil: uma narrativa por meio de seu ensino. Psicologia: Ciência e Profissão, 32(n. esp. ), 28-43.

Vendramini, C. M. M., Silva, M. C. R. \& Dias, A. E. (2009). Avaliação de atitudes em estudantes de psicologia via modelo de créditos parciais da TRI. Psico-USF, 14(3), 287-298.

\author{
Endereço para correspondência \\ Rodolfo Augusto Matteo Ambiel \\ Universidade São Francisco - USF \\ Rua Waldemar César da Silveira, 105, Jardim Cura D'Ars (SWIFT), CEP 13045-510, \\ Campinas - SP, Brasil \\ Endereço eletrônico: rodolfo.ambiel@usf.edu.br
}

Makilim Nunes Baptista

Universidade São Francisco - USF

Rua Waldemar César da Silveira, 105, Jardim Cura D'Ars (SWIFT), CEP 13045-510,

Campinas - SP, Brasil

Endereço eletrônico: makilim.baptista@usf.edu.br

Marucia Patta Bardagi

Universidade Federal de Santa Catarina - UFSC

Laboratório de Informação e Orientação Profissional (LIOP)

Campus J oão David Ferreira Lima, s/n, Trindade, CEP 88040-900, Florianópolis - SC, Brasil

Endereço eletrônico: marucia.bardagi@gmail.com

Acácia Aparecida Angeli dos Santos

Universidade São Francisco - USF

Rua Waldemar César da Silveira, 105, Jardim Cura D'Ars (SWIFT), CEP 13045-510,

Campinas - SP, Brasil

Endereço eletrônico: acacia.santos@usf.edu.br

Recebido em: 25/08/2015

Reformulado em: 21/09/2017

Aceito em: 29/09/2017 
Rodolfo Augusto Matteo Ambiel, Makilim Nunes Baptista, Marucia Patta Bardagi, Acácia Aparecida Angeli dos Santos

\section{Notas}

* Psicólogo, Doutor em Psicologia pela Universidade São Francisco. Atualmente é docente do Programa de Pós-graduação Stricto Sensu em Psicologia da Universidade São Francisco (área de concentração em Avaliação Psicológica). Editor-chefe da Revista Psico-USF (Qualis A2). Bolsista Produtividade CNPq 2.

** Psicólogo, Doutor em Psicologia pela Universidade Federal de São Paulo (UNIFESP). Atualmente é docente do Programa de Pós-graduação Stricto Sensu em Psicologia da Universidade São Francisco (área de concentração em Avaliação Psicológica). Bolsista Produtividade CNPq 1 C.

*** Psicóloga, Mestre e Doutora em Psicologia pela Universidade Federal do Rio Grande do Sul (UFRGS). Atualmente é docente licenciada da Universidade Federal de Santa Catarina (UFSC).

**** Psicóloga, Doutora em Psicologia pela Universidade de São Paulo. Atualmente é docente do Programa de Pós-graduação Stricto Sensu em Psicologia da Universidade São Francisco (área de concentração em Avaliação Psicológica). Bolsista Produtividade CNPq 1A.

O presente trabalho foi realizado com apoio da Coordenação de Aperfeiçoamento de Pessoal de Nível Superior - Brasil (CAPES) - Código de Financiamento 001.

Este artigo de revista Estudos e Pesquisas em Psicologia é licenciado sob uma Licença Creative Commons Atribuição-Não Comercial 3.0 Não Adaptada. 